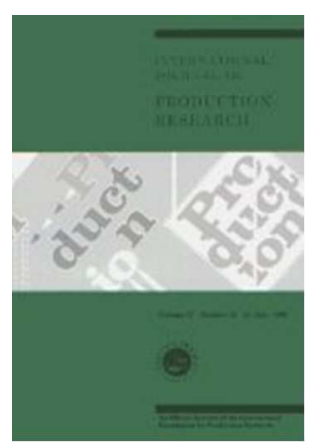

\title{
A JOINT PRICING, LOT-SIZING AND SUPPLIER SELECTION MODEL
}

\begin{tabular}{|c|c|}
\hline Journal: & International Journal of Production Research \\
\hline Manuscript ID: & TPRS-2011-IJPR-0171.R1 \\
\hline Manuscript Type: & Original Manuscript \\
\hline $\begin{array}{l}\text { Date Submitted by the } \\
\text { Author: }\end{array}$ & 30-May-2011 \\
\hline Complete List of Authors: & $\begin{array}{l}\text { Rezaei, Jafar; Delft University of Technology, Netherlands, Department of } \\
\text { Technology, Strategy \& Entrepreneurship } \\
\text { Davoodi, Mansoor; Amirkabir University of Technology, Department of } \\
\text { Mathematics and Computer Science }\end{array}$ \\
\hline Keywords: & $\begin{array}{l}\text { SUPPLIER SELECTION, LOT SIZING, SUPPLY CHAIN MANAGEMENT, } \\
\text { EVOLUTIONARY ALGORITHMS, GENETIC ALGORITHMS }\end{array}$ \\
\hline Keywords (user): & \\
\hline
\end{tabular}

SCHOLARONE ${ }^{m}$

Manuscripts 


\title{
A JOINT PRICING, LOT-SIZING AND SUPPLIER SELECTION MODEL
}

\author{
Jafar Rezaei $^{1, *}$ and Mansoor Davoodi ${ }^{2}$ \\ ${ }^{l}$ Department of Technology, Strategy and Entrepreneurship, Faculty of Technology, Policy and Management, Delft \\ University of Technology, P.O. Box 5015, 2600 GA Delft, The Netherlands. \\ ${ }^{2}$ Laboratory of Algorithms and Computational Geometry, Department of Mathematics and Computer Science, Amirkabir \\ University of Technology, Tehran, Iran.
}

\begin{abstract}
In this paper, we integrate the three strategies that are important to most firms, namely pricing, lot-sizing and supplier selection. Combining the three objectives of total profit, inconsistency and deficiency with a set of constraints, we formulate this integrated problem as a multi-objective non-linear programming model, proposing a genetic algorithm (NSGA-II) that provides decision-makers with a number of Pareto-optimal solutions, one of which can be selected on the basis of the higher-level information. We analyze the trade-off between the different Paretooptimal solutions and discuss the results of that analysis. We then evaluate the performance of NSGA-II compared to SPEA2 in solving the model, which shows NSGA-II performs better. Finally, concluding remarks and suggestions for future research are provided.

Keywords: lot-sizing, pricing, supplier selection, supply chain management, multi-objective optimization, non-linear programming, genetic algorithm, NSGA-II, SPEA2

\footnotetext{
* Corresponding author, Tel.: +31(0)1527 82985, Fax: +31(0) 152783177

E-mail: j.rezaei@tudelft.nl (J. Rezaei), mdmonfared@aut.ac.ir (M. Davoodi)
} 


\title{
A JOINT PRICING, LOT-SIZING AND SUPPLIER SELECTION MODEL
}

\begin{abstract}
In this paper, we integrate the three strategies that are important to most firms, namely pricing, lot-sizing and supplier selection. Combining the three objectives of total profit, inconsistency and deficiency with a set of constraints, we formulate this integrated problem as a multiobjective non-linear programming model, proposing a genetic algorithm (NSGA-II) that provides decision-makers with a number of Pareto-optimal solutions, one of which can be selected on the basis of the higher-level information. We analyze the trade-off between the different Pareto-optimal solutions and discuss the results of that analysis. We then evaluate the performance of NSGA-II compared to SPEA2 in solving the model, which shows NSGA-II performs better. Finally, concluding remarks and suggestions for future research are provided. Keywords: lot-sizing, pricing, supplier selection, supply chain management, multi-objective optimization, non-linear programming, genetic algorithm, NSGA-II, SPEA2
\end{abstract}

\section{Introduction}

Wagner and Whitin (1958) are among the first researchers who formulated the lot-sizing problem, as one of the most important problems facing most firms. They considered a situation with a single product and multiple periods and solved the problem using a dynamic programming algorithm. However, they only considered inventory management costs. In recent decades, various aspects of this basic problem have been studied extensively. For detailed information regarding its classifications and characteristics, see, for instance, Yano and Lee (1995), Karimi et al. (2003), Ben-Daya et al. (2008) and Robinson et al. (2009).

Supplier selection is another fundamental and important decision firms (buyers) have to make. While most studies in this area have focused on a multi-criteria framework, taking into account criteria like quality, delivery, price and geographical location (e.g. de Boer et al., 2001; Wilson, 1994; Weber et al., 1991; Kannan and Haq, 2007, Ho et al., 2010), some have examined the problem in a multi-objective framework (e.g. Weber and Ellram, 1992; Ghodsypour and O’Brien, 1998; Karpak, et al., 1999; Amid et al., 2011). 
Taking into account the increasing importance of supply chain management and attempting to align different strategies available to buyers, some researchers have combined the two important problems mentioned above (lot-sizing and supplier selection) (Tempelmeier, 2002; Liao and Kuhn, 2004; Basnet and Leung, 2005; Rezaei and Davoodi, 2006, 2008, 2011; Liao and Rittscher, 2007; Cheng and Ye, 2010), bringing together qualitative and quantitative metrics for supplier selection, and inventory costs for lot-sizing, and applying mathematical programming to account for the constraints of the integrated system. For a review of this approach, see Aissaoui et al. (2007).

A third important decision facing buyers involves determining the selling price or pricing. Abad (1994) has drawn a distinction based on two assumptions: 1) annual demand for the item is fixed and the buyer only has to plan his procuring (i.e. lot-sizing) policy; 2) annual demand is a function of the price. When the latter is the case, buyers are faced with decisions regarding prices and lot-size. These two areas are examined together in a number of studies (e.g. Abad, 1994, 1996, 2001, 2003a, 2003b; Hwang and Shinn, 1997; Kim and Lee, 1998; Shinn and Hwang, 2003; Chen and Chen, 2004; Rezaei, 2005; Khouja, 2006; Smith et al., 2007, 2009; Gonzalez-Ramirez et al., 2011).

In this paper, we combine the three problems outlined above. We consider a situation in which a buyer has to decide which products to order in what quantities, and from which suppliers and when, as well as determine the selling price of each product in each period. In this situation, as in most actual situations, we assume that demand for the products depends on selling prices, while the buyer has a limited budget at the first stage of his planning horizon. Based on the assumption that the buyer wants to maximize total profits and minimize total inconsistency and deficiency under a set of constraints - including suppliers' capacity, warehouse storage and budget limitations - we formulate a multi-objective non-linear mixed integer programming model. Because this is a problem that basically belongs to a class of NPhard problems (Florian et al., 1980; Bitran and Yanasse, 1982), a suitable approach to dealing with the problem is by using a heuristic search algorithm. In this paper, we use a robust multiobjective genetic algorithm and introduce a new operator called Refiner operator, to satisfy the constraints of the problem efficiently. 
The remainder of this paper is organized as follows. In section two, we present the details and mathematical modeling of the problem and discuss the heuristic genetic algorithm in section three. Section four contains the numerical example, discussion and comparison study. In section five, we present our conclusions and suggestions for future research.

\section{Mathematical modeling}

The mathematical model in this paper has been developed on the basis of the following notations and assumptions.

\section{Notations}

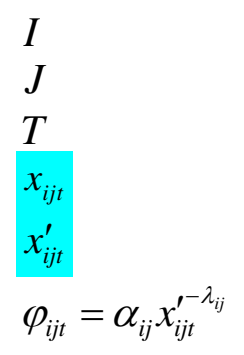

Number of products

Number of suppliers

Number of periods

Number of product $i$ ordered to supplier $j$ in period $t$

Number of good product $i$ delivered by supplier $j$ in period $t$

Purchasing price of product $i$ from supplier $j$ in period $t$ given purchased quantity $x_{i j t}^{\prime}$

$\alpha_{i j} \quad$ Scaling constant of purchasing price $\varphi_{i j t}$

$\lambda_{i j} \quad$ Degree of economy of scale regarding purchasing price $\varphi_{i j t}$

$p_{i t} \quad$ Selling price of product $i$ in period $t$

$u_{i j}^{l} \quad$ Late delivery rate of product $i$ offered by supplier $j$

$u_{i j}^{w} \quad$ Wrong delivery rate of product $i$ offered by supplier $j$

$\delta_{i j} \quad$ Inconsistency (late and wrong deliveries) reduction rate of product $i$ offered by supplier $j$

$q_{i j} \quad$ Deficiency rate of product $i$ offered by supplier $j$

$\eta_{i j}$

Deficiency reduction rate of product $i$ offered by supplier $j$

$o_{j}$

Fixed ordering cost for supplier $j$

$o_{j}^{\prime} x_{i j t}^{\gamma_{j}}$

Variable ordering cost for supplier $j$

$\tau_{j}$

Transportation cost of supplier $j$ per vehicle

$n_{j t}$

Number of vehicles assigned for supplier $j$ in period $t$

$y_{j t}$

Binary integer: 1 -if the order is given to supplier $j$ in period $t, 0$-otherwise

$B_{t}$

Total budget of buyer in period $t, B_{0}=$ initial budget

$h_{i} \quad$ Holding cost of product $i$ per period

$d_{i t}\left(p_{i t}\right) \quad$ Total demand of product $i$ in period $t$ given price $p_{i t}$; where $d_{i t}\left(p_{i t}\right)=m_{i t}-\beta_{i t} p_{i t}$, for all $i, t$ and $d d_{i k}\left(p_{i k}\right) / d p_{i k}<0$.

$m_{i t} \quad$ Deterministic proportion of overall demand of product $i$ in period $t, m_{i t}>0$ 
$\beta_{i t} \quad$ Sensitivity of demand of product $i$ to selling price $p_{i t}$ in period $t, \beta_{i t}>0$

$c_{i j} \quad$ Capacity of supplier $j$ in production of product $i$ per period

$w_{i} \quad$ Space occupied by product $i$ in the warehouse or vehicle

$W \quad$ Total storage capacity

$v_{j} \quad$ Vehicle capacity of supplier $j$

$I_{i t} \quad$ Inventory of product $i$ in period $t$

\section{Assumptions}

1) The purchasing price depends on the purchased quantity, while the selling price depends on customer demand.

2) Ordering costs are a combination of fixed costs, which are independent of the lot-size, and additional ordering costs, which depend on the specific lot-size.

3) The buyer has a limited storage capacity and budget in each period.

4) Suppliers have limited supply capacity.

5) Initial and final inventory levels of all the products are zero.

6) Shortage is not allowed, i.e. the demand for each product within each period should be completely satisfied within the same period.

Based on these notations and assumptions, we present the details of the mathematical programming model, which contains three objective functions and a set of constraints.

\section{Objective functions}

Total profit $\left(z_{1}\right)$ : the total profit in this situation is computed as the difference between total revenues and total costs, where the total revenues are earned by selling all the products in all periods and the total costs are the sum of the purchasing costs, ordering costs, holding costs, and transportation costs in all periods. The buyer wants to maximize total profits. Here, we elaborate on some parts of this objective function. According to Aissaoui et al. (2007), in modeling the problems of lot-sizing and supplier selection, there are two general situations with regard to purchasing price: items without discount and items with discount. Quantity discount is offered to maximize profits. When discount is continuous, the buyer obtains more information about prices, which can be used in supplier comparison (Schotanus et al. 2009). In this paper, the purchasing price, $\alpha_{i j} x_{i j t}^{\prime-\lambda_{i j}}$, is lot-size-supplier dependent. $\alpha_{i j}$ is the scaling constant of purchasing price, and $x_{i j t}^{\prime-\lambda_{i j}}$ indicates the effect of purchased quantity on 
purchasing price such that the higher the purchased quantity $x_{i j t}^{\prime}$, the lower the purchasing price. $\lambda_{i j}$ is the degree of economy of scale regarding purchasing price. In fact it shows the degree to which supplier $j$ reduces the price reacting to increasing the purchased quantity of product $i$ by the buyer. It is clear that, if supplier $j$ offers item $i$ without discount, or equivalently does not react to the increasing of purchased quantity by the buyer at all, then $\lambda_{i j}=0$ and $\alpha_{i j} x_{i j t}^{\prime-\lambda_{i j}}=\alpha_{i j}$. Ordering costs consist of a fixed cost $o_{j}$, which is independent of the lot-size, and an additional (variable) ordering cost $o_{j}^{\prime} x_{i j t}^{\gamma_{j}}$, which depends on the specific lot-size. It is clear that we include the variable ordering cost just because in this case it depends on the lot-size. Otherwise, it is independent of the ordering policy and can be excluded from the model. To formulate the fixed cost $o_{j}$, we should first consider different possible relationships between supplier and buyer. Figure 1 shows six types of relationship that have been identified in literature, together with the key emphasis and focus of the relationship, clustered into three categories: adversarial, partnership and integrated (Hines, 2004). Because integrated relationships imply that two firms operate as one, we do not consider them here. Existing literature mainly implicitly assumes that there is an arm's length (adversarial) relationship between buyer and supplier, which means it has to be assumed that the buyer pays a fixed amount in ordering cost for every order. However, when we consider the commitment that exists between buyer and supplier in partnership types of relationship, it is wise to assume that, for a continuous period of time, the buyer pays the fixed ordering cost only once, rather than with every order. However, the variable ordering costs $o_{j}^{\prime} x_{i j t}^{\gamma_{j}}$ depend on the specific lot-size in each period. As the last part of the first objective function, we consider transportation costs, which have often been ignored in solving lot-sizing problems (Rezaei and Davoodi, 2011; Aissaoui et al., 2007; Ertogral et al., 2007; van Norden and van de Velde, 2005). As mentioned by Aissaoui et al. (2007), one of the advantages of the synergy generated by multi-item models is the possibility of reducing transportation costs. For example, in multiitem models, it is possible to benefit from transporting multiple items in a single vehicle, which is why we assume that different items purchased from a supplier can be transferred by a single vehicle, within the capacity of that vehicle.

Consequently, the buyer's total profits are formulated as follows: 
$\max z_{1}=\sum_{i} \sum_{t}\left[p_{i t}\left(I_{i t-1}+\sum_{j} x_{i j t}^{\prime}-I_{i t}\right)-\sum_{j} \alpha_{i j} x_{i j t}^{1-\lambda_{i j}}-\sum_{j} o_{j}^{\prime} x_{i j t}^{1-\gamma_{j}}-h_{i} I_{i t}\right]-\sum_{j} \sum_{t}\left(o_{j} \max \left\{0, y_{j t}-y_{j t-1}\right\}+\tau_{j} n_{j t}\right)$

\section{INSERT FIGURE 1 ABOUT HERE}

Total inconsistency $\left(z_{2}\right)$ : Inconsistency is defined as the percentage of late and wrong delivery by the supplier. With regard to late delivery, inconsistency is the percentage of time delayed, whereas in the case of wrong delivery it is the percentage of goods returned (Beamon, 1998; Mapes et al., 2000; Chan, 2003). Service level is defined as the percentage of lots that are completed before or on the due date, while inconsistency rate is a measure that is broader than the measure of service level that has thus far been used in multi-objective supplier selection literature (e.g. Amid et al., 2006; Rezaei and Davoodi, 2011). In this paper, we define an integrated measure for the inconsistency rate of product $i$ offered by supplier $j$ as a combination of late delivery $\left(u_{i j}^{l}\right)$ and wrong delivery $\left(u_{i j}^{w}\right)$. Regardless the effect of longterm relationship on late and wrong delivery, this performance criterion (inconsistency) would be $u_{i j}^{l}+u_{i j}^{w}$. Several studies, however, have shown that long-term relationship helps suppliers reduce late and wrong deliveries (e.g. Kalwani and Narayandas, 1995; Horvath, 2001). We therefore make an exponential relationship between the constant level of inconsistency $\left(u_{i j}^{l}+u_{i j}^{w}\right)$ and the frequency of the relationship between buyer and supplier $j\left(\sum_{k=1}^{t} y_{j k}\right)$ as $\left(u_{i j}^{l}+u_{i j}^{w}\right) e^{-\delta_{i j} \sum_{k=1}^{t} y_{j k}}$ i.e. the more frequent relationship between buyer and supplier $j$, the lower the level of supplier's inconsistency. $\delta_{i j}$ is the degree to which supplier $j$ reduces inconsistencies (late and wrong deliveries) reacting to increasing the frequency of the relationship by the buyer. If the frequency of the relationship would not be important for supplier $j$ to decrease the level of inconsistency at all, then $\delta_{i j}=0$ and $\left(u_{i j}^{l}+u_{i j}^{w}\right) e^{-\delta_{i j} \sum_{k=1}^{t} y_{j k}}=u_{i j}^{l}+u_{i j}^{w}$. Because it is in the buyer's interest to minimize the total inconsistency with regard to all suppliers within the planning horizon, this objective function is constructed as follows: 


$$
\min z_{2}=\sum_{i} \sum_{j} \sum_{t}\left(u_{i j}^{l}+u_{i j}^{w}\right) e^{-\delta_{i j} \sum_{k=1}^{t} y_{j k}} x_{i j t}
$$

It is assumed that items that are delivered late are delivered by the end of the next period and items that are delivered wrongly are rejected both at the expense of the supplier.

Total deficiency $\left(z_{3}\right)$ : the buyer wants to minimize the total number of defective items delivered by suppliers. We define the defective rate $q_{i j}$ as the percentage of product $i$ delivered by supplier $j$ as defective. Regardless the effect of relationship frequency on delivering defective items by the supplier, the performance criterion, deficiency, would be $q_{i j}$. Deficiency indicates one important aspect of a supplier's performance, which, like other aspects, can be improved via a long-term relationship between buyer and supplier (Larson, 1994). To see the effect of long-term relationship between buyer and supplier on a supplier's capabilities and performance, we refer to studies conducted in the area of supplier development (e.g. Wagner and Krause, 2009). To show this effect in this objective function, we make an exponential function between the constant level of a supplier's deficiency $q_{i j}$, and the frequency of the relationship between buyer and supplier $\sum_{k=1}^{t} y_{j k}$ as $q_{i j} e^{-\eta_{i j} \sum_{k=1}^{t} y_{j k}}$ which means that more frequent relationship between buyer and supplier may lead to lower level of deficiency. $\quad \eta_{i j}$ is the degree to which supplier $j$ decreases the amount of delivered defective item $i$ reacting to increasing the frequency of the relationship by the buyer. If the frequency of the relationship would not be important for supplier $j$ to reduce the deficiencies at all, then $\eta_{i j}=0$ and $q_{i j} e^{-\eta_{i j} \sum_{k=1}^{t} y_{j k}}=q_{i j}$. The following objective function reflects the minimization of total deficiency:

$$
\min z_{3}=\sum_{i} \sum_{j} \sum_{t} q_{i j} e^{-\eta_{i j} \sum_{k=1}^{t} y_{j k}} x_{i j t}
$$

It is assumed that defective items are rejected at the expense of the supplier.

In general, we expect that there is a trade-off between the first objective function and the other two objective functions. One may argue that, when trying to maximize the total profit, 
the buyer should accept some more inconsistencies or deficiencies of the suppliers. For example, the buyer will prefer to purchase products from suppliers who offer their products at a lower price (to maximize the first objective function). In most real-world cases, however, this implies more late and long deliveries and more defective items (which refer to the second and third objective functions). In addition, while the existence of a close relationship between buyer and supplier may reduce a supplier's inconsistency and deficiency (refer to the exponential relationship between order frequency and supplier's performance in second and third objective functions), it may reduce the total profit, for example by increasing transportation costs.

\section{Constraints}

The following constraints apply to our model:

Demand constraint: this constraint ensures that the demand for each product within each period is satisfied within the same period.

$\sum_{k=1}^{t} \sum_{j} x_{i j k}^{\prime}-\sum_{k=1}^{t} d_{i k} \geq 0$, for all $i$ and $t$

Ordering costs: this constraint ensures that the buyer cannot place an order without having to pay appropriate ordering costs. Because of the dependency of variable ordering costs on lotsize, this constraint relates only to the fixed part of the total ordering costs. Note that this constraint is not in conflict with the fifth term (ordering cost) of the first objective function.

$\left(\sum_{k=t}^{T} d_{i k}\right) y_{j t}-x_{i j t} \geq 0$, for all $i, j$ and $t$

Budget limitation: This constraint shows the limitation of the buyer's budget for purchasing, inventory and transportation costs.

$\sum_{i} \sum_{j} \alpha_{i j} x_{i j t}^{\prime-\lambda_{i j}}-g_{t-1}+B_{t}-B_{t-1}=0$, for all $t$

( $g_{t}$ is defined at (26))

Storage capacity: Because the buyer has a limited storage space $W$ and each product $i$ occupies $w_{i}$ of this space, only a limited number of products can be kept in storage at the end of each period. 
$\sum_{i} w_{i} I_{i t} \leq W$, for all $t$

( $I_{i t}$ is defined at (27))

Initial and final inventory level: This constraint expresses the assumption that the initial and the final inventory level are zero. However, the decision-maker (buyer) can determine the threshold for these levels.

$I_{i 0}=I_{i T}=0$, for all $i$

Demand-price function: In pricing and lot-sizing problems, two demand functions have been commonly been considered: (1) the constant price-elasticity function, and (2) the linear demand function (e.g. Abad, 1988, 1994, 2003b; Khouja, 2006; Gonzalez-Ramirez et al., 2011). Here, we assume that the selling price of product $i$ in period $t, p_{i t}$, depends on the demand for this product in period $t$ as a linear demand function:

$d_{i t}=m_{i t}-\beta_{i t} p_{i t}$, for all $i$ and $t$

Supplier capacity: This constraint ensures that the number of products $i$ ordered from supplier $j$ in period $t$ is equal to or less than the capacity of this supplier to deliver this product. $x_{i j t} \leq c_{i j} \quad$ for all $i, j$ and $t$

Binary and non-negativity constraints:

$y_{j t}=\left\{\begin{array}{ll}1, & \text { if there exists } i: x_{i j t}>0 ; \\ 0, & \text { if for all } i: x_{i j t}=0 .\end{array}\right.$ for all $j$ and $t$,

$x_{i j t} \geq 0$ for all $i, j$ and $t$ and $B_{t} \geq 0$ for all $t$

The resulting model looks as follows:

$\max z_{1}=\sum_{i} \sum_{t}\left[p_{i t}\left(I_{i t-1}+\sum_{j} x_{i j t}^{\prime}-I_{i t}\right)-\sum_{j} \alpha_{i j} x_{i j t}^{1-\lambda_{i j}}-\sum_{j} o_{j}^{\prime} x_{i j t}^{1-\gamma_{j}}-h_{i} I_{i t}\right]-\sum_{j} \sum_{t}\left(o_{j} \max \left\{0, y_{j t}-y_{j t-1}\right\}+\tau_{j} n_{j t}\right)$

$$
\begin{aligned}
& \min z_{2}=\sum_{i} \sum_{j} \sum_{t}\left(u_{i j}^{l}+u_{i j}^{w}\right) e^{-\delta_{i j} \sum_{k=1}^{t} y_{j k}} x_{i j t} \\
& \min z_{3}=\sum_{i} \sum_{j} \sum_{t} q_{i j} e^{-\eta_{i j} \sum_{k=1}^{t} y_{j k}} x_{i j t}
\end{aligned}
$$


S.t.

$\sum_{k=1}^{t} \sum_{j} x_{i j k}^{\prime}-\sum_{k=1}^{t} d_{i k} \geq 0$, for all $i$ and $t$

$\left(\sum_{k=t}^{T} d_{i k}\right) y_{j t}-x_{i j t} \geq 0$, for all $i, j$ and $t$

$\sum_{i} \sum_{j} \alpha_{i j} x_{i j t}^{1-\lambda_{i j}}-g_{t-1}+B_{t}-B_{t-1}=0$, for all $t$

$\sum_{i} w_{i} I_{i t} \leq W$, for all $t$

$I_{i 0}=I_{i T}=0$, for all $i$

$d_{i t}=m_{i t}-\beta_{i t} p_{i t}$, for all $i$ and $t$

$0 \leq x_{i j t} \leq c_{i j}$ for all $i, j$ and $t$

$y_{j t}=\left\{\begin{array}{ll}1, & \text { if there exists } i: x_{i j t}>0 \\ 0, & \text { if for all } i: x_{i j t}=0,\end{array}\right.$ for all $j$ and $t$

$B_{t} \geq 0$, for all $t$

where

$x_{i j t}^{\prime}=x_{i j t}\left(1-u_{i j t}-q_{i j t}+u_{i j t} q_{i j t}\right)+x_{i j t-1} u_{i j t-1}^{l}\left(1-q_{i j t-1}\right)$, for all $i, j$ and $t$

$u_{i j t}=\left(u_{i j}^{l}+u_{i j}^{w}\right) e^{-\delta_{i j} \sum_{k=1}^{t} y_{j k}}, u_{i j t}^{l}=u_{i j}^{l} e^{-\delta_{i j} \sum_{k=1}^{t} y_{j k}}$ and $q_{i j t}=q_{i j} e^{-\eta_{i j} \sum_{k=1}^{t} y_{j k}}$, for all $i, j$ and $t$

$g_{t}=\sum_{i}\left[p_{i t}\left(I_{i t-1}+\sum_{j} x_{i j t}^{\prime}-I_{i t}\right)-\sum_{j} o_{j}^{\prime} x_{i j t}^{1-\gamma_{j}}-h_{i} I_{i t}\right]-\sum_{j}\left(o_{j} \max \left\{0, y_{j t}-y_{j t-1}\right\}+\tau_{j} n_{j t}\right)$, for all $t$

$I_{i t}=\left(I_{i t-1}+\sum_{j} x_{i j t}^{\prime}-d_{i t}\right)$, for all $i$ and $t$

$n_{j t}=\left\lceil\frac{\sum_{i} w_{i} x_{i j t}\left(1-u_{i j t}^{l}\right)}{v_{j}}\right\rceil$, for all $j$ and $t$

This problem is a typical multi-objective non-linear combinatorial problem, which we solve using a genetic algorithm. In the next section, we take a closer look at the proposed genetic algorithm. 


\section{Genetic algorithm}

When optimizing a single objective problem, the goal is to find the best single design solution. However, for multi-objective problems with several (possibly conflicting) objectives, no single optimal solution is usually available, which means that the decision-maker has to select a solution from a finite set by making compromises. Since most actual optimization problems involve a trade-off between various conflicting objectives, for example minimum inconsistency or deficiency and maximum profits, the main goal of solving a Multi-Objective Optimization Problem (MOOP) is to provide a set (handful) of the best trade-off solutions, or Pareto-optimal solutions, which are a key tool in the decision-making process. In fact, an ideal MOO algorithm must identify a diverse set of Pareto-optimal solutions in the objective space. Because classical search and optimization methods use a point-by-point approach, they obtain a single optimized (optimal) solution. However, in Evolutionary Algorithms (EAs), a population of solutions is applied in each iteration, which means that EAs are more suitable when it comes to realizing the twin goals of solving MOO problems (optimality and diversity). Genetic Algorithm (GA) is a robust EA that is applied to many MOOPs, in particular to production and operations management problems. For a review of the application of GA in production and operations management see for example Aytug et al. (2003), Chaudhry and Luo (2005) and Guner Goren et al. (2010). GA is a probabilistic search technique that is very suitable for large, complex, non-convex, discrete search space or illbehaved objective functions (Goldberg, 1989; Deb, 2001).

In the last two decades, many researchers have tried to present multi-objective version of GA. Most well-known algorithms, like NSGA-II (Deb et al., 2000) and SPEA2 (Zitzler et al., 2001), are based on non-domination solutions. The non-domination solution of a genetic population is the best solution of population such that there is no better solution with regard to all the objectives. By emphasizing non-domination solutions, these algorithms try to move toward Pareto-optimal solutions. More precisely, in an optimization (minimization) problem, a decision vector $x \in S$ is called Pareto-optimal if there is no other vector $y \in S$ such that $Z_{i}(y)$ $\leq Z_{i}(x)$ for all $i=1, \ldots, M$, and $Z_{j}(y)<Z_{j}(x)$ for at least one index $j$. In addition, an objective vector is Pareto-optimal if the corresponding decision vector is Pareto-optimal. Some 
approaches have been proposed to determine a Pareto set, for instance Deb (2001), Jensen (2003) and Chen et al. (2009).

Generally speaking, Multi Objective Evolutionary Algorithms (MOEAs) use a nondominated principle and satisfy two orthogonal objectives simultaneously:

- Optimality: All the points have to be non-dominated solutions and near to Paretooptimal fronts of problem.

- Diversity: The set of solutions must not be limited to a subset of the Pareto frontier.

Many algorithms that use the above-mentioned principle are described by Deb (2001). One of the best algorithms is elitist Non-dominated Sorting Genetic Algorithm (NSGA-II), which uses the non-domination rule and sorts all solutions of a genetic population and divides the population into various preferred levels of non-domination in each generation. Because this approach only satisfies the first task of MOOPs, most MOEAs use several techniques, for example niche operators and counting metrics. These techniques use density of solution around a solution in population and increase or decrease the ranking of the solution. In NSGA-II, after each front has been created, its members are assigned crowding distances (normalized distance to closest neighbors in the front in objective space). Based on Deb (2001), the NSGA-II procedure is outlined as follows:

\section{NSGA-II Algorithm}

Step 1: Combine parent and offspring populations and create $R_{t}=P_{t} \cup Q_{t}$. Perform a nondominated sorting to $R_{t}$ and identify different fronts: $F_{i}, i=1,2, \ldots$, etc.

Step 2: Set the new population $P_{t}=\varnothing$ and $i=1$.

Until $\left|P_{t+1}\right|+\left|F_{i}\right|<N$ perform $P_{t+1}=P_{t+1} \cup F_{i}$ and $i=i+1$.

Step 3: For the remaining capacity in $P_{t+1}$, perform the crowding operators and fill it by some of the best solutions in $F_{i}$.

Step 4: Create offspring population $Q_{t+1}$ from $P_{t+1}$ by using some crossover and mutation operators.

$N$ is a population size (parent and offspring). In the following subsections, we describe GA operators and other aspects to solve the model. 


\section{Chromosome Representation}

The representation process, which is the initial step of a GA, can have a strong influence on the definition and efficiency of GA operators. Generally speaking, there are two binary or real representations of each solution in GA. If $I, J$ and $T$ represent the number of products, suppliers and periods, respectively, each chromosome is an integer vector $x$ by length $I \times J \times T$, a real vector $p$ by length $I \times T$ and a binary vector $y$ by length $J \times T$, appropriate by each $x_{i j t}, p_{i t}$ and $y_{j t}$. Figure 2 presents a schematic view of a chromosome used in this study.

\section{INSERT FIGURE 2 ABOUT HERE}

\section{Initialize of population}

Since no useful information regarding the location of Pareto-optimal solution in search space is available, in the multi-dimensional optimization problems, especially in MOO problems, the initialization step of a GA population is completely random. However, in this study, we satisfy constraints (20) and (21) of our model. Since $d_{i t}\left(p_{i t}\right) \geq 0$, we use uniform integer random generator in interval $\left[0, \beta_{i t} / m_{i t}\right]$ to initialize $p_{i t}$ and uniform integer random generator in set $\left\{0,1, \ldots, c_{i j}\right\}$ to initialize $x_{i j t}$. Also, we hold this satisfaction in the GA process (after crossover and mutation operators). Similarly, random binary generator for $y$ vector is used.

\section{Fitness, Constraints satisfaction and Selection strategy}

Because the selection is based on chromosome evaluation, this is a main step of a GA. Since feasibility is the first goal in constrained optimizations, we use an elegant method to satisfy the three aspects (evaluation, selection mechanism and constraints satisfaction) efficiently in a single step. The model we introduce contains three objectives and seven constraints (equations 15-21 in the model). As mentioned earlier, we satisfy bound constraints (equations 20,21 and 22 for $x, p$ and $y$ variables) in the initial population and hold this property while the GA process is continued. To satisfy other constraints, we use the refiner operator which is introduced next, and the constrained tournament selection operator. In fact, several approaches have been presented to satisfy constraints of MOO problems, for instance ignoring infeasible chromosomes, penalty function, JVGS, constrained tournament, etc. (Michalewicz and Schoenauer, 1996; Jimenez et al., 1999; Deb, 2001). We use the 
constrained tournament method because of its ability to satisfy constraints and selection based on fitness simultaneously (unlike other approaches, like roulette wheel and proportionate selection). It has been shown that tournament selection operator has better or equivalent convergence rate and complexity time compared to other selection operators introduced in the literature (Goldberg and Deb, 1991). Additionally, tournament operator is free from the scaling problem which is happened in large and non-dense search spaces (Deb, 2001). In fact, the constrained tournament selection operator combines the domination principle and constraint satisfaction, by first selecting two (or more) chromosomes from the population and then determining a winner via the following rules:

- Feasible solutions are better than non-feasible solutions.

- Between two feasible solutions (or two infeasible solutions), the standard domination identifies the winning solution.

In the latter rule, the constrained tournament selection operator looks at objective functions (the first goal of MOO) and then at the diversity of solutions in the population (the second goal of MOO). Several approaches have been presented to achieve diversity, including niche metrics, crowding models, sharing functions, etc. (Deb, 2001). In this paper, we use a crowding distance based on the average distance of a solution in objective space.

\section{Crossover operator}

The 'variation' operator is a combination of various operators (such as crossover and mutation) that are used to generate a modified population. Crossover operators combine information from two parents (solutions of current population) in such a way that the two children (solutions for a next population) resemble both parents. Several methods have been introduced to realize this combination (Michalewicz, 1994; Deb, 2001). Since, in this study, each chromosome contains three vectors $x$ (integer vector), $p$ (real vector), and $y$ (binary vector), we use a single-point linear crossover to combine $x$ and $p$ vectors of two parents, and a single-point multiple replacement for vectors $y$, to produce two offspring solutions. As the chromosome representation is real code, this type of crossover is faster than binary crossover. The following pseudo-code describes crossover operation in our implementation: 
$\lambda=$ Random real value between 0 and $\operatorname{Max}_{\lambda}$

cpx = integer number between 0 and $I \times J \times T$

$\begin{cases}C 1\left(x_{i j t}\right)=\lambda P 1\left(x_{i j t}\right)+(1-\lambda) P 2\left(x_{i j t}\right), & \text { if } i \times j \times t<c p x \\ C 2\left(x_{i j t}\right)=\lambda P 2\left(x_{i j t}\right)+(1-\lambda) P 1\left(x_{i j t}\right), & \text { otherwise }\end{cases}$

cpp = integer number between 0 and $I \times T$

$\begin{cases}C 1\left(p_{i t}\right)=\lambda P 1\left(p_{i t}\right)+(1-\lambda) P 2\left(p_{i t}\right), & \text { if } i \times t<c p p \\ C 2\left(p_{i t}\right)=\lambda P 2\left(p_{i t}\right)+(1-\lambda) P 1\left(p_{i t}\right), & \text { otherwise }\end{cases}$

cpy $=$ integer number between 0 and $J \times T$

$\begin{cases}C 1\left(y_{j t}\right)=P 1\left(y_{j t}\right), & \text { if } j \times t<c p y \\ C 1\left(y_{j t}\right)=P 2\left(y_{j t}\right), & \text { otherwise } \\ C 2\left(y_{j t}\right)=P 2\left(y_{j t}\right), & \text { if } j \times t<c p y \\ C 2\left(y_{j t}\right)=P 1\left(y_{j t}\right), & \text { otherwise }\end{cases}$

In the current population, $P 1$ and $P 2$ are two selected parents, while $C 1$ and $C 2$ are two children. After using the linear crossover, we first round the result (because $x$ is an integer vector) and check its lower and upper bounds (constraints 20 and 21) for $x$ and $p$ for $\operatorname{Max}_{\lambda}$ value greater than one. Also, to avoid small positive values of $x_{i j t}$ for some $i, j$ and $t$ in the final non-dominated optimal solutions, we define a lower bounded parameter $L B x$, which is user-predefined. To end this, after generating a solution in the algorithm it's $x_{i j t}$ value is set to zero or $L B x^{*} d_{i t}$ if it falls between 0 and $L B x^{*} d_{i t}$.

\section{Mutation operator}

Each offspring solution created by the crossover operator is perturbed in its vicinity by a mutation operator (Goldberg, 1989). Every variable is mutated with a predefined mutation probability. In this study, we use a linear mutation by probability $1 / I \times J \times T$ to mutate $x$, $1 / I \times T$ for $p$ vectors and a bit-wise mutation by probability $1 / J \times T$ for $y$ vector as follows:

For mutation in $x$ (or $p$ ), first a random member $x_{i j t}$ (or $p_{i t}$ ) is selected, after which a new random value is selected with regard to the upper and lower bounds. Similarly, for $y$, a single cell is selected at random, after which its value is replaced by 1 if it is 0 , and vice versa. 


\section{Refiner operator}

Finding a feasible solution in the constrained optimization problems is a challenging problem in literature (Deb, 2001). The model proposed in this paper is a constrained problem, with some hard constraints (e.g. equations 17 and 19). Although the constrained tournament selection operator helps the algorithm to move the population toward the feasible regions in the search space, it is a time-consuming process and too many generations of the algorithm are needed. Another problem that arises in this case is that, after finding a feasible solution, since other solutions of population are infeasible, they converge to the feasible solution or to the feasible region that is found the first time. Therefore, achieving the second objective of MOOP (finding a diverse set of Pareto-optimal solutions) becomes very difficult. To overcome this problem, we introduce a new operator, which is called a refiner operator, and which we use after the crossover and mutation operator. Selecting the solutions with a smaller constraint violation as a winner in each tournament is designed to move the population toward a feasible region. Orthogonally to this idea, our refiner operator tries to move each child solution toward the nearest feasible region. In fact, the refiner operator has a local approach to changing an infeasible solution to a feasible solution.

If $s$ is a solution that is obtained by using crossover and mutation operators and if $s$ is an infeasible solution, the refiner operator changes $s$ to a feasible solution or an infeasible solution, with smaller constraint violation in a random way. To end this, we have three options: $x, y$ and $p$, which construct a solution to the problem. First, we compute the value of constraint violation based on the constraint of the model. For any violation in the equation 15 , refiner operator decreases $d_{i t}$ by increasing the value of $p_{i t}$, randomly. Also, for any violation in the constraint equation 16 , the value of $x_{i j t}$ is decreased with regard to $L B x$ bounded parameter, randomly, or sets value of $y_{j t}$ to 1 . Finally, this process is repeated for satisfying the hard constraints by increasing or decreasing the value of $x_{i j t}$ for some random selected $i, j$ and $t$.

\section{Termination condition}

The GA operators are repeated until a termination criterion is met. In the MOO problems, because of the goal (obtaining a set of diverse Pareto-optimal solutions), only some criteria (relative to single objective optimization), such as reaching a maximum number of generations and finding a special set of solutions, can be used. However, although identifying an exact and 
efficient terminate condition is an arduous empirical affair, it can be determined with regard to the size of population, complexity of search space and number of final non-dominated solutions. In the simulation that is performed in this paper, we use a population size 120,10 final non-dominated solutions and a maximum of 500 iterations.

It should be mentioned here that, mutation rate, the size of population, and the number of iterations were obtained after a pilot testing.

\section{Numerical example}

In this section, we illustrate the formulated model and solve the problem, using the proposed genetic algorithm. We consider a situation with three products, four periods and four suppliers. The relevant data is presented in Tables 1 and 2.

\section{INSERT TABLES 1 AND 2 ABOUT HERE}

Solving this model simultaneously provides the buyer with the optimal values of the selling price, total demand, purchasing price and lot-size of different products in different periods. The model proposed in this paper is a multi-objective model that uses a genetic algorithm, providing the buyer with various optimal solutions, allowing the buyer to select the most suitable solution based on higher-level information. For this example, we produce 10 non-dominated solutions (Sol. 1 through Sol. 10). However, it is clear that, in a real-world situation, a decision-maker may consider more optimal solutions.

The results are presented in Tables 3-7. Table 3 shows the selling price of product $i$ in period $t$ in ten non-dominated solutions, which in turn dictate the corresponding optimal values of total demand (see Table 4). It should be mentioned here that, in the proposed model there are three constraints that can potentially lead to inventory shortage: budget limitation (equation 6); storage capacity (equation 7); and supplier's capacity (equation 10). However equation 4 dictates that inventory shortage is not allowed. The relationship between customer demand and the buyer's selling price (see equation 9) guarantees the prevention of inventory shortage, i.e. the demand-price relationship equation determines the customer demand such that all the mentioned conflicting constraints (equations 4, 6, 7, and 10) will be satisfied.

\section{INSERT TABLES 3 AND 4 ABOUT HERE}

Once the total demand of the three products in four periods is determined, the buyer has to order the products from the four suppliers. Tables 5 and 6 show the optimal number of product 
$i$ purchased from supplier $j$ in period $t$ in the ten non-dominated solutions and their corresponding purchasing price respectively. It should be mentioned here that, to avoid small values for $x_{i j t}$, we set the $L B x$ parameter to 0.1 , which results in an optimal $x_{i j t}$ of zero or greater than ten percent of the total demand for product $i$ in period $t$. As can be seen from Table 5, among four suppliers, two suppliers (suppliers 1 and 4 ) have been selected (all $x_{i j t}=$ 0 , for $j=2$ and 3 ). Note that the values in Table 5 are optimal lot-sizes $x_{i j t}$, which are different from $x_{i j t}^{\prime}$. $x_{i j t}^{\prime}$ can be obtained from (24). In Table 6, we have included the corresponding purchasing prices of $x_{i j t}$. It is clear that, when $x_{i j t}=0$, there is no value for the purchasing price.

Finally, Table 7 and Figure 3 show the optimal value of objective functions for the ten non-dominated solutions and the trade-off between them.

\section{INSERT TABLES 5, 6, 7 AND FIGURE 3 ABOUT HERE}

It becomes clear that, when total profits are increased, the value of at least one of the other two objective functions also increases. In other words, to increase profits, the buyer has to sacrifice at least one of the other two objectives. The fourth row of Table 7 also shows the changes in value of objective functions between the non-dominated solutions. For example when comparing Sol.2 to Sol.1, the value of objective functions $z_{1}, z_{2}$ and $z_{3}$ decreases, which means that Sol.2 is worse than Sol.1 in terms of the total profit, while it is better than Sol.1 in terms of total inconsistency and deficiency. As mentioned before, this trade-off between objective values allows the buyer to choose the most suitable solution from the set of nondominated solutions based on higher-level information. Among the ten non-dominated solutions, Sol.8 and Sol.2 are the best solutions with respect to total profit, and total inconsistency and total deficiency respectively.

\section{Comparison results}

To compare the performance of the proposed NSGA-II algorithm in presence of the refiner operator, we apply SPEA2, as another popular and powerful multi-objective evolutionary optimization algorithm (Zitzler et al., 2001), to solve the problem. SPEA2 uses a fixed-size external population in addition to a main genetic population for achieving non-dominated solutions and updates it in each generation. When the number of non-dominated solutions exceeds the size of the external population, the algorithm uses a simple clustering approach to select some of them such that the selected set is as diverse as possible. Also, to deal with 
elitism, SPEA2 uses a global strategy and combines both the genetic and external populations to generate the next child population. Several comparison studies have been done to compare NSGA-II and SPEA2 in solving some standard test problems (Deb, 2001, Khare et al., 2002, Konak et al., 2006). Here we compare NSGA-II in the presence of the proposed refiner operator with SPEA2 in solving the proposed model. To this end, we use the spacing metric (Schott, 1995) to compare diversity, and the set coverage metric (scm) (Zitzler et al., 2000) to compare Pareto-optimality of the final obtained solutions. The spacing metric computes the distance between any two consecutive solutions in the objective space as follows:

$$
\begin{aligned}
& d_{i}=\min _{\substack{j=1, \ldots, n \\
j \neq i}} \sum_{m=1}^{M}\left|f_{m}^{i}-f_{m}^{j}\right|, \\
& \bar{d}=\frac{1}{n} \sum_{i=1}^{n} d_{i}, \\
& S=\sqrt{\frac{1}{n} \sum_{i=1}^{n}\left(d_{i}-\bar{d}\right)^{2}},
\end{aligned}
$$

where, $M$ is the number of objectives, $f_{m}^{i}$ is the value of $m$ th objective for solution $i$, and $n$ is the number of the obtained solutions. This metric is used to measure the spread of the solutions. A smaller spacing value $S$ shows a better diversity.

Also, for two sets of solutions $A$ and $B, \operatorname{scm}(A, B)$ measures the amount of closeness of the solutions to the Pareto-optimal fronts. It computes the proportion of the solutions in $B$ that are weakly dominated by the solutions in $A$. So, the $\operatorname{scm}(A, B)$ is calculated as follows:

$$
\operatorname{scm}(A, B)=\frac{\{\{b \in B \mid \exists a \in A: a \preceq b\} \mid}{|B|},
$$

where $\preceq$ corresponds to the weak dominance relation. If $\operatorname{scm}(A, B)$ closes to one and $\operatorname{scm}(B, A)$ closes to zero, the solution set $A$ dominates to the solution set $B$.

To have a fair comparison between SPEA2 and NSGA-II in the presence of the refiner operator, we set all the genetic parameters as the same as those of NSGA-II, and set the size of the external population of SPEA2 to 30 which is $1 / 4$ of the size of the main population (120). This ratio has been commonly used by the pioneers of SPEA2 (Zitzler et al. 2001, Deb 2001).

We separately run each algorithm 30 times, and compare their results with respect to the above-mentioned metrics. To this end, we first compute spacing and set coverage of each 
obtained solution set. Then, we use the non-parametric Wilcoxon rank sum test to examine the differences between two independent samples of obtained results from the two algorithms NSGA-II and SPEA2 with respect to two metrics (set coverage and spacing). The comparison results are shown in Table 8.

\section{INSERT TABLE 8 ABOUT HERE}

Based on the results of Wilcoxon rank sum test, it is concluded that the set coverage of NSGA-II (median $=0.888)$ is significantly better than the set coverage of SPEA2 (median = 0.171). However the difference between the spacing of NSGA-II (median $=0.0019$ ) and that of SPEA2 $($ median $=0.0014)$ is not significant. The comparison results show the suitability and better performance of NSGA-II algorithm in the presence of the refiner operator to solve the specific problem of this paper.

\section{Conclusion and future research}

In this paper, we have considered a situation in which a buyer wants to find the optimal selling price and lot-size of multiple products in multiple periods, while at the same time selecting the best suppliers. Taking into account the objectives of total profits, total inconsistency and total deficiency and a number of constraints, including budget limitation, storage and supplier capacity, we have formulated a multi-objective non-linear mixed integer programming model, applying a genetic algorithm (NSGA-II) to solve the model and produce a handful of Pareto-optimal solutions. Although the buyer is faced with some constraints, such as budget limitation, storage capacity and suppliers' limited capacity, the buyer still is able to prevent inventory shortage which is because of the relationship between the buyer's selling price and customer demand. In addition, we have analyzed the trade-offs between the various solutions that allow the buyer to select the most suitable solution based on higher-level information, which is to a considerable extent qualitative and subjective in nature and which cannot be formulated within the model. Furthermore we compared the results obtained by NSGA-II with another popular and powerful multi-objective evolutionary optimization algorithm, SPEA2. The comparison results show the robustness of NSGA-II algorithm in the presence of the proposed refiner operator to solve the specific problem of this paper.

For future research we suggest applying other multi-objective evolutionary optimization algorithms (e.g. Caballero et al., 2004; Davarynejad et al., 2011) to solve this problem. We 
also suggest incorporating other features of the buyer-supplier relationship in examining and modeling the problem of lot-sizing and supplier selection. Finally, while we have formulated the problem in terms of deterministic conditions, the inclusion of stochastic, probabilistic and fuzzy formulations of the model is recommended.

\section{References}

Abad, P.L., 1988. Joint price and lot-size determination when supplier offers incremental quantity discounts. The Journal of the Operational Research Society, 39(6), 603-607.

Abad, P.L., 1994. Supplier pricing and lot-sizing when demand is price sensitive. European Journal of Operational Research, 78(3), 334-354.

Abad, P.L., 1996. Optimal pricing and lot-sizing under conditions of perishability and partial backordering. Management Science, 42, 1093-1104.

Abad, P.L., 2001. Optimal price and order size for a reseller under partial backordering. Computers \& Operations Research, 28, 53-65.

Abad, P.L., 2003a. Optimal price and lot-size when the supplier offers a temporary price reduction over an interval. Computers \& Operations Research, 30(1), 63-74.

Abad, P.L., 2003b. Optimal pricing and lot-sizing under conditions of perishability, finite production and partial backordering and lost sale. European Journal of Operational Research, 144(3), 677-685.

Aissaoui, N., Haouari, M., and Hassini, E. 2007. Supplier selection and order lot-sizing modeling: A review. Computers \& Operations Research, 34 (12), 3516-3540.

Amid, A., Ghodsypour, S.H. and O’Brien, C., 2006. Fuzzy multiobjective linear model for supplier selection in a supply chain. International Journal of Production Economics 104, 394-407.

Amid, A., Ghodsypour, S.H. and O’Brien, C., 2011. A weighted max-min model for fuzzy multi-objective supplier selection in a supply chain, International Journal of Production Economics, 131 (1), 139-145.

Aytug, H., Khouja, M. and Vergara, F. E., 2003. Use of genetic algorithms to solve production and operations management problems: a review, International Journal of Production Research, 41(17), 3955 - 4009. 
Basnet, C. and Leung, J.M.Y., 2005. Inventory lot-sizing with supplier selection, Computers \& Operations Research, 32, 1-14.

Beamon, B.M., 1998. Supply Chain Design and Analysis: Models and Methods, International Journal of Production Economics, 55 (3), 281-294.

Ben-Daya, M., Darwish, M. and Ertogral, K., 2008. The joint economic lot-sizing problem: Review and extensions. European Journal of Operational Research, 185(2), 726-742.

Bitran, G.R. and Yanasse, H.H., 1982. Computational complexity of the capacitated lot-size problem. Management Science, 28(10), 1174-1186.

Caballero, R., Gandibleux, X. and Molina, J., 2004. MOAMP-A Multiobjective Metaheuristic using an Adaptative Memory Procedure. Technical Report. University of Valenciennes.

Chan, F.T.S., 2003. Performance measurement in a supply chain. The International Journal of Advanced Manufacturing Technology, 21, 534-548.

Chaudhry, S.S. and Luo, W., 2005. Application of genetic algorithms in production and operations management: a review, International Journal of Production Research, 43(19), $4083-4101$.

Chen, E.J. and Lee, L.H., 2009. A multi-objective selection procedure of determining a Pareto set, Computer \& operation research, 36, 1872-1879.

Chen, J.M. and Chen, L.T., 2004. Pricing and lot-sizing for a deteriorating item in a periodic review inventory system with shortages, Journal of the Operational Research Society, 55, 892-901.

Cheng, F. and Ye, F., 2010, A two objective optimisation model for order splitting among parallel suppliers, International Journal of Production Research, DOI: 10.1080/00207541003792250.

Davarynejad, M., Rezaei, J., Vrancken, J., van den Berg, J. and Coello Coello, C.A., 2011. Accelerating convergence towards the optimal Pareto front. 2011 IEEE Congress on Evolutionary Computation, June 5-8, 2011, New Orleans, USA.

de Boer, L., Labro, E. and Morlacchi, P., 2001. A review of methods supporting supplier selection. European Journal of Purchasing and Supply Management, 7, 75-89.

Deb, K., 2001. Multi-Objective Optimization using Evolutionary Algorithms. Chichester, U.K., Wiley. 
Deb, K., Agrawal, S., Pratap, A. and Meyarivan, T., 2000. A fast elitist non-dominated sorting genetic algorithm for multi-objective: NSGA-II. In: Proceedings of the Parallel Problem Solving from Nature VI Conference, Springer-Verlag, pp. 846-858.

Ertogral, K., Darwish, M., and Ben-Daya, M. 2007. Production and shipment lot sizing in a vendor-buyer supply chain with transportation cost, European Journal of Operational Research, 176(3), 1592-1606.

Florian, M., Lenstra, J.K. and Rinnooy Kan, A.H.G., 1980. Deterministic Production Planning: Algorithms and Complexity. Management Science, 26(7), 669-679.

Ghodsypour, S.H. and O'Brien, C., 1998. A decision support system for supplier selection using an integrated analytic hierarchy process and linear programming. International Journal of Production Economics, 56-57, 199-212.

Goldberg, D. E. and Deb, K., 1991. A comparison of selection schemes used in genetic algorithm, In Foundations of genetic algorithms 1 (FOGA), 69-63.

Goldberg, D.E., 1989. Genetic Algorithms in Search, Optimization, and Machine Learning. Addison Wesley.

Gonzalez-Ramirez, R. G., Smith, N. R. and Askin, R. G., 2011. A heuristic approach for a multi-product capacitated lot-sizing problem with pricing, International Journal of Production Research, 49(4), 1173-1196.

Guner Goren, H., Tunali, S. and Jans, R., 2010. A review of applications of genetic algorithms in lot sizing, Journal of Intelligent Manufacturing, 21(4), 575-590.

Hines, A., 2004. Supply Chains Strategies; Customer Driven and Customer-Focused, Butterworth-Heinemann, Oxford.

Ho, W., Xu, X. and Dey, P. K., 2010. Multi-criteria decision making approaches for supplier evaluation and selection: A literature review, European Journal of Operational Research, 202(1), 16-24.

Horvath, L., 2001. Collaboration: the key to value creation in supply chain management, Supply Chain Management: An International Journal, 6(5), 205 - 207.

Hwang, H. and Shinn, S.W., 1997. Retailer's pricing and lot-sizing policy for exponentially deteriorating products under the condition of permissible delay in payments. Computers \& Operations Research, 24, 539-547. 
Jensen, M.T., 2003. Reducing the run-time complexity of Multiobjective EAs: the NSGA-II and other algorithms, IEEE Transaction on Evolutionary Computation, 7 (5), 503-515.

Jimenez, F., Verdegay, J.L. and Gomez-Skarmeta, A.F., 1999. Evolutionary techniques for constrained multiobjective optimization problems. In: Proceedings of the Workshop on Multi-Criterion Optimization Using Evolutionary Methods held at Genetic and Evolutionary Computation Conference, GECCO, pp. 115-116.

Kalwani, M.U., and Narayandas, N., 1995. Long-term manufacturer-supplier relationships: do they pay off for supplier firms?, The Journal of Marketing, 59(1), 1-16.

Kannan, G. and Haq A.N., 2007. Analysis of interactions of criteria and sub-criteria for the selection of supplier in the built-in-order supply chain environment. International Journal of Production Research, 45(17) 3831 - 3852.

Karimi, B., Fatemi Ghomi, S.M.T. and Wilson, J.M., 2003. The capacitated lot-sizing problem: a review of models and algorithms. Omega, 31, 365- 378.

Karpak, B., Birsen, K., Rammohan, R. And Kumcu, E., 1999. Multi-objective decisionmaking in supplier selection: An application of visual interactive goal programming. Journal of Applied Business Research, 15(2), 57-71.

Khare V., Yao X. and Deb K., 2002. Performance scaling of multi-objective evolutionary algorithms, KanGAL Report No. 2002009, 1-15.

Khouja, M., 2006. A joint optimal pricing, rebate value, and lot-sizing model. European Journal of Operational Research, 174(2), 706-723.

Kim, D. and Lee, W.J., 1998. Optimal joint pricing and lot-sizing with fixed and variable capacity. European Journal of Operational Research, 109 (1), 212-227.

Konak A., Coit A.W. and Smith, A.E. 2006. Multi-objective optimization using genetic algorithms: A tutorial, Reliability Engineering and System Safety, 91(9), 992-1007.

Larson, P.D., 1994. Buyer-supplier co-operation, product quality and total costs, International Journal of Physical Distribution \& Logistics Management, 24(6), 4-10.

Liao, Z. and Kuhn, A., 2004. Operational integration of supplier selection and procurement lot-sizing in supply chain. Proceedings of global project and manufacturing management symposium, Siegen Germany. 
Liao, Z. and Rittscher, J., 2007. A multi-objective supplier selection model under stochastic demand conditions. International Journal of Production Economics, 105, 150-159.

Mapes, J., Szwejczewski, M. and New, C., 2000. Process variability and its effect on plant performance. International Journal of Operations and Production Management, 20(7), 792-808.

Michalewicz, Z. and Schoenauer, M., 1996. Evolutionary algorithms for constrained parameter optimization problems. Evolutionary Computation Journal, 4(1), 1-32.

Michalewicz, Z., 1994. Genetic algorithms + data structures = evolution programs. AI Series, Springer Verlag, New York.

Rezaei, J. and Davoodi, M., 2006. Genetic algorithm for inventory lot-sizing with supplier selection under fuzzy demand and costs. Advances in Applied Artificial Intelligence, vol. 4031, 1100-1110.

Rezaei, J. and Davoodi, M., 2008. A deterministic, multi-item inventory model with supplier selection and imperfect quality. Applied Mathematical Modelling 32(10), 2106-2116.

Rezaei, J. and Davoodi, M., 2011. Multi-objective models for lot-sizing with supplier selection, International Journal of Production Economics, 130(1), 77-86.

Rezaei, J., 2005. An inventory control model with price-demand relationship in a fuzzy environment, $3^{\text {rd }}$ International Management Conference, September 20-22, 2005 Tehran, Iran.

Robinson, P., Narayanan, A., and Sahin, F., 2009. Coordinated deterministic dynamic demand lot-sizing problem: A review of models and algorithms. Omega, 37(1), 3-15.

Schotanus, F., Telgen, J., and de Boer, L., 2009. Unraveling quantity discounts. Omega, 37(3), $510-521$.

Schott, J.R. 1995. Fault Tolerant Design Using Single and Multi-Criteria Genetic Algorithms. Master's Thesis, Boston, MA: Department of Aeronautics and Astronautics, Massachusetts Institute of Technology.

Shinn, S.W. and Hwang H., 2003. Optimal pricing and ordering policies for retailers under order-size-dependent delay in payments. Computers \& Operations Research, 30(1) 35-50. 
Smith, N.R, Martínez-Flores, J.L. and Cárdenas-Barrón L.E., 2007. Analysis of the benefits of joint price and order quantity optimisation using a deterministic profit maximisation model. Production Planning and Control, 18(4), 310-318.

Smith, N.R., Limón, J., and Cárdenas-Barrón, L.E., 2009. Optimal pricing and production master planning in a multi period horizon considering capacity and inventory constraints, Mathematical Problems in Engineering, 2009, 1-15.

Tempelmeier, H., 2002. A simple heuristic for dynamic order sizing and supplier selection with time-varying data. Production and Operations Management, 11, 499-515.

van Norden, L., and van de Velde, S., 2005. Multi-product lot-sizing with a transportation capacity reservation contract, European Journal of Operational Research, 165(1), 127-138.

Wagner, H.M. and Whitin, T.M., 1958. Dynamic version of the economic lot-size model. Management Science, 5, 89-96.

Wagner, S.M. and Krause, D.R., 2009. Supplier development: communication approaches, activities and goals, International Journal of Production Research, 47(12), 3161-3177.

Weber, C.A. and Ellram, L.M., 1992. Supplier selection using multi-objective programming: a decision support system approach. International Journal of Physical Distribution \& Logistics Management, 23 (2), 3-14.

Weber, C.A., Current, J.R. and Benton, W.C., 1991. Vendor selection criteria and methods. European Journal of Operational Research, 50, 2-18.

Wilson, E.J., 1994. The relative importance of supplier selection criteria: A review and update. International Journal of Purchasing and Materials Management, 30, 35-41.

Yano, C.A. and Lee, H.L., 1995. Lot-sizing with random yields: A review. Operations Research, 43 (2), 311-334.

Zitzler, E., Deb, K. and Thiele, L., 2000. Comparison of Multiobjective Evolutionary Algorithms: Empirical Results. Evolutionary Computation, 8(2), 173-195.

Zitzler, E., Laumanns, M. and Thiele, L., 2001. SPEA2: Improving the strength Pareto evolutionary algorithm for multi-objective optimization, Evolutionary Methods for Design Optimization and Control with Applications to Industrial Problems, pp. 95-100. 
Table 1 Holding cost, occupied space and demand components of product $i$

\begin{tabular}{cccrrrc}
\hline Product $(i)$ & $h_{i}$ & $w_{i}$ & $m_{i 1}, \beta_{i 1}$ & $m_{i 2}, \beta_{i 2}$ & $m_{i 3}, \beta_{i 3}$ & $m_{i 4}, \beta_{i 4}$ \\
\hline 1 & 23 & 0.2 & $500,3.6$ & $620,4.5$ & $550,3.9$ & $470,4.1$ \\
2 & 21 & 0.15 & $770,4.9$ & $700,4.7$ & $580,3.8$ & $660,3.15$ \\
3 & 6 & 0.16 & $160,1.8$ & $150,1.7$ & $215,2.1$ & $290,2.7$ \\
\hline
\end{tabular}

Table 2 Other data related to products and/or suppliers

\begin{tabular}{cccccc}
\hline & & \multicolumn{5}{c}{ Suppliers } \\
\cline { 2 - 6 }$\alpha_{i j}, \lambda_{i j}$ & 1 & $57,0.01$ & 2 & 3 & 4 \\
& 2 & $84,0.02$ & $85,0.02$ & $55,0.01$ & $62,0.015$ \\
& 3 & $25,0.01$ & $27,0.01$ & $80,0.01$ & $79,0.03$ \\
\hline$u_{i j}^{l}, u_{i j}^{w}, \delta_{i j}$ & 1 & $0.0,0.02,0.08$ & $0.01,0.0,0.09$ & $0.02,0.02$ & $29,0.02$ \\
\hline & 2 & $0.01,0.0,0.11$ & $0.001,0.1,0.1$ & $0.0,0.02,0.08$ & $0.01,0.01,0.1$ \\
& 3 & $0.003,0.01,0.1$ & $0.01,0.1,0.15$ & $0.01,0.001,0.1$ & $0.01,0.0,0.06$ \\
\hline$q_{i j}, \eta_{i j}$ & 1 & $0.005,0.1$ & $0.001,0.01$ & $0.005,0.09$ & $0.007,0.06$ \\
& 2 & $0.01,0.05$ & $0.005,0.05$ & $0.01,0.08$ & $0.004,0.08$ \\
& 3 & $0.01,0.05$ & $0.01,0.1$ & $0.012,0.1$ & $0.003,0.11$ \\
\hline$c_{i j}$ & 1 & 150 & 65 & 90 & 120 \\
& 2 & 200 & 80 & 130 & 110 \\
\hline$o_{j}$ & 3 & 100 & 90 & 250 & 90 \\
$o_{j}^{\prime}, \gamma_{j}$ & & 950 & 1180 & 1320 & 1090 \\
$v_{j}$ & & $0.1,0.001$ & $0.09,0.003$ & $0.7,0.002$ & $0.1,0.002$ \\
$\tau_{j}$ & 44 & 76 & 76 & 22 \\
$W=60, B_{0}=75000$ & 220 & 385 & 385 & 105 \\
\hline
\end{tabular}


Table 3 Selling price of product $i$ in period $t$ in ten non-dominated solutions

\begin{tabular}{|c|c|c|c|c|c|c|c|c|c|c|}
\hline$p_{i t}$ & Sol. 1 & Sol. 2 & Sol. 3 & Sol. 4 & Sol. 5 & Sol. 6 & Sol. 7 & Sol. 8 & Sol. 9 & Sol. 10 \\
\hline$p_{11}$ & 92.97 & 100.54 & 75.82 & 86.17 & 80.55 & 98.80 & 86.18 & 89.76 & 77.05 & 91.92 \\
\hline$p_{12}$ & 104.51 & 99.49 & 102.62 & 105.80 & 96.78 & 91.56 & 94.04 & 81.33 & 103.77 & 94.10 \\
\hline$p_{13}$ & 96.47 & 107.75 & 96.43 & 107.33 & 93.64 & 92.36 & 102.76 & 91.89 & 114.56 & 95.17 \\
\hline$p_{14}$ & 94.22 & 90.86 & 95.05 & 77.16 & 92.60 & 68.93 & 94.16 & 75.05 & 78.35 & 81.29 \\
\hline$p_{21}$ & 131.48 & 126.84 & 126.77 & 122.69 & 103.04 & 121.68 & 115.36 & 102.93 & 112.76 & 103.33 \\
\hline$p_{22}$ & 122.54 & 130.34 & 112.95 & 117.76 & 102.89 & 92.97 & 110.76 & 98.57 & 128.23 & 113.44 \\
\hline$p_{23}$ & 128.82 & 121.34 & 106.68 & 115.61 & 115.38 & 104.61 & 118.08 & 105.41 & 126.44 & 125.89 \\
\hline$p_{24}$ & 168.02 & 167.16 & 166.13 & 155.75 & 137.70 & 144.59 & 163.92 & 144.43 & 161.40 & 150.01 \\
\hline$p_{31}$ & 35.80 & 44.41 & 43.32 & 39.55 & 36.97 & 46.23 & 40.67 & 50.04 & 38.74 & 46.43 \\
\hline$p_{32}$ & 52.76 & 55.70 & 56.19 & 61.16 & 40.02 & 42.34 & 37.91 & 49.46 & 43.54 & 37.10 \\
\hline$p_{33}$ & 58.04 & 49.43 & 54.34 & 38.97 & 35.35 & 53.51 & 58.36 & 42.45 & 37.05 & 45.34 \\
\hline$p_{34}$ & 76.79 & 74.23 & 52.43 & 79.52 & 62.50 & 52.05 & 59.48 & 61.78 & 72.81 & 52.01 \\
\hline
\end{tabular}

Table 4 Total demand of product $i$ in period $t$ given price $p_{i t}$ for ten non-dominated solutions

\begin{tabular}{rrrrrrrrrrr}
\hline$d_{i t}$ & \multicolumn{1}{c}{ Sol. 1 } & \multicolumn{1}{c}{ Sol. 2 } & \multicolumn{1}{c}{ Sol. 3 } & \multicolumn{1}{c}{ Sol. 4 } & \multicolumn{1}{c}{ Sol. 5 } & \multicolumn{1}{l}{ Sol. 6 } & \multicolumn{1}{c}{ Sol. 7 } & \multicolumn{1}{c}{ Sol. 8 } & \multicolumn{1}{|c}{ Sol. 9 } & Sol. 10 \\
\hline$d_{11}$ & 165.30 & 138.04 & 227.05 & 189.80 & 210.03 & 144.32 & 189.76 & 176.85 & 222.63 & 169.08 \\
$d_{12}$ & 149.70 & 172.29 & 158.22 & 143.89 & 184.49 & 207.97 & 196.83 & 253.99 & 153.03 & 196.56 \\
$d_{13}$ & 173.75 & 129.78 & 173.94 & 131.43 & 184.79 & 189.80 & 149.25 & 191.62 & 103.22 & 178.83 \\
$d_{14}$ & 83.71 & 97.49 & 80.29 & 153.65 & 90.34 & 187.37 & 83.92 & 162.31 & 148.75 & 136.69 \\
$d_{21}$ & 125.75 & 148.48 & 148.81 & 168.79 & 265.11 & 173.77 & 204.75 & 265.62 & 217.46 & 263.67 \\
$d_{22}$ & 124.05 & 87.39 & 169.16 & 146.51 & 216.43 & 263.06 & 179.41 & 236.74 & 97.32 & 166.85 \\
$d_{23}$ & 90.48 & 118.91 & 174.62 & 140.68 & 141.55 & 182.50 & 131.29 & 179.43 & 99.53 & 101.63 \\
$d_{24}$ & 130.75 & 133.46 & 136.68 & 169.39 & 226.23 & 204.54 & 143.64 & 205.06 & 151.59 & 187.48 \\
$d_{31}$ & 95.56 & 80.06 & 82.03 & 88.81 & 93.46 & 76.78 & 86.80 & 69.93 & 90.27 & 76.42 \\
$d_{32}$ & 60.31 & 55.32 & 54.48 & 46.03 & 81.96 & 78.02 & 85.56 & 65.93 & 75.99 & 86.94 \\
$d_{33}$ & 93.11 & 111.20 & 100.90 & 133.17 & 140.76 & 102.63 & 92.44 & 125.86 & 137.20 & 119.78 \\
$d_{34}$ & 82.66 & 89.58 & 148.44 & 75.31 & 121.26 & 149.46 & 129.41 & 123.20 & 93.42 & 149.57 \\
\hline
\end{tabular}


Table 5 Number of product $i$ purchased from supplier $j$ in period $t$ in ten non-dominated

\begin{tabular}{rrrrrrrrrrr}
\multicolumn{10}{c}{ Solutions (all $x_{i j t}=0$, for $j=2$ and 3) } \\
\hline$x_{i j 1}$ & Sol. 1 & Sol. 2 & Sol. 3 & Sol. 4 & Sol. 5 & Sol. 6 & Sol. 7 & Sol. 8 & Sol. 9 & Sol. 10 \\
\hline$x_{111}$ & 150 & 126 & 150 & 150 & 139 & 90 & 143 & 150 & 138 & 150 \\
$x_{112}$ & 150 & 86 & 104 & 150 & 76 & 150 & 150 & 150 & 150 & 77 \\
$x_{113}$ & 150 & 150 & 150 & 139 & 96 & 150 & 150 & 150 & 150 & 150 \\
$x_{114}$ & 0 & 0 & 32 & 0 & 49 & 37 & 0 & 81 & 0 & 63 \\
$x_{141}$ & 90 & 66 & 100 & 95 & 97 & 58 & 52 & 85 & 91 & 72 \\
$x_{142}$ & 15 & 120 & 88 & 67 & 91 & 78 & 119 & 55 & 85 & 84 \\
$x_{143}$ & 29 & 0 & 0 & 14 & 92 & 120 & 0 & 45 & 0 & 76 \\
$x_{144}$ & 0 & 0 & 28 & 16 & 42 & 60 & 18 & 84 & 26 & 22 \\
\hline$x_{211}$ & 135 & 175 & 130 & 183 & 173 & 68 & 132 & 160 & 111 & 159 \\
$x_{212}$ & 0 & 0 & 24 & 16 & 132 & 156 & 107 & 168 & 0 & 98 \\
$x_{213}$ & 106 & 0 & 200 & 121 & 128 & 165 & 167 & 130 & 152 & 124 \\
$x_{214}$ & 0 & 0 & 17 & 0 & 88 & 75 & 0 & 112 & 0 & 39 \\
$x_{241}$ & 13 & 96 & 109 & 18 & 97 & 109 & 110 & 110 & 110 & 110 \\
$x_{242}$ & 110 & 110 & 110 & 110 & 86 & 109 & 110 & 70 & 98 & 68 \\
$x_{243}$ & 110 & 110 & 0 & 96 & 110 & 110 & 0 & 110 & 10 & 92 \\
$x_{244}$ & 0 & 0 & 44 & 86 & 42 & 38 & 38 & 34 & 89 & 35 \\
\hline$x_{311}$ & 78 & 0 & 66 & 100 & 64 & 66 & 9 & 28 & 80 & 37 \\
$x_{312}$ & 39 & 0 & 9 & 5 & 29 & 43 & 60 & 8 & 87 & 65 \\
$x_{313}$ & 51 & 75 & 99 & 81 & 100 & 60 & 100 & 100 & 14 & 66 \\
$x_{314}$ & 0 & 0 & 15 & 0 & 32 & 24 & 0 & 0 & 0 & 30 \\
$x_{341}$ & 67 & 83 & 69 & 55 & 34 & 39 & 90 & 44 & 82 & 76 \\
$x_{342}$ & 47 & 90 & 82 & 51 & 68 & 55 & 90 & 90 & 90 & 75 \\
$x_{343}$ & 53 & 90 & 0 & 47 & 90 & 90 & 0 & 90 & 0 & 50 \\
$x_{344}$ & 0 & 0 & 50 & 8 & 25 & 34 & 49 & 28 & 48 & 38 \\
\hline & & & & & & & & & & \\
\hline
\end{tabular}


Table 6 Purchasing price of product $i$ from supplier $j$ in period $t$ given order quantity $x_{i j t}$ for ten non-dominated solutions

\begin{tabular}{ccccccccccc}
\hline$\varphi_{i 1 t}$ & Sol. 1 & Sol. 2 & Sol. 3 & Sol. 4 & Sol. 5 & Sol. 6 & Sol. 7 & Sol. 8 & Sol. 9 & Sol. 10 \\
\hline$\varphi_{111}$ & 54.23 & 54.32 & 54.23 & 54.23 & 54.27 & 54.50 & 54.25 & 54.23 & 54.27 & 54.23 \\
$\varphi_{112}$ & 54.23 & 54.53 & 54.42 & 54.23 & 54.60 & 54.23 & 54.23 & 54.23 & 54.23 & 54.59 \\
$\varphi_{113}$ & 54.22 & 54.22 & 54.22 & 54.27 & 54.47 & 54.22 & 54.22 & 54.22 & 54.22 & 54.22 \\
$\varphi_{114}$ & & & 55.07 & & 54.83 & 54.99 & & 54.56 & & 54.70 \\
$\varphi_{141}$ & 57.97 & 58.25 & 57.88 & 57.93 & 57.91 & 58.36 & 58.45 & 58.02 & 57.97 & 58.17 \\
$\varphi_{142}$ & 59.50 & 57.72 & 57.98 & 58.22 & 57.95 & 58.09 & 57.73 & 58.39 & 58.01 & 58.03 \\
$\varphi_{143}$ & 58.96 & & & 59.58 & 57.95 & 57.72 & & 58.57 & & 58.11 \\
$\varphi_{144}$ & & & 59.00 & 59.49 & 58.62 & 58.31 & 59.39 & 58.03 & 59.06 & 59.19 \\
\hline$\varphi_{211}$ & 76.18 & 75.78 & 76.24 & 75.72 & 75.80 & 77.23 & 76.21 & 75.92 & 76.48 & 75.93 \\
$\varphi_{212}$ & & & 78.78 & 79.34 & 76.19 & 75.95 & 76.51 & 75.83 & & 76.64 \\
$\varphi_{213}$ & 76.54 & & 75.58 & 76.34 & 76.24 & 75.86 & 75.84 & 76.22 & 75.99 & 76.29 \\
$\varphi_{214}$ & & & 79.27 & & 76.81 & 77.05 & & 76.45 & & 78.05 \\
$\varphi_{241}$ & 73.18 & 68.92 & 68.66 & 72.47 & 68.90 & 68.66 & 68.64 & 68.64 & 68.64 & 68.64 \\
$\varphi_{242}$ & 68.63 & 68.62 & 68.62 & 68.63 & 69.12 & 68.63 & 68.62 & 69.54 & 68.85 & 69.60 \\
$\varphi_{243}$ & 68.62 & 68.62 & & 68.89 & 68.62 & 68.62 & & 68.62 & 73.57 & 68.99 \\
$\varphi_{244}$ & & & 70.55 & 69.12 & 70.60 & 70.80 & 70.86 & 71.04 & 69.07 & 70.98 \\
\hline$\varphi_{311}$ & 23.94 & & 23.98 & 23.88 & 23.99 & 23.98 & 24.46 & 24.19 & 23.93 & 24.12 \\
$\varphi_{312}$ & 24.10 & & 24.46 & 24.59 & 24.18 & 24.08 & 24.00 & 24.49 & 23.91 & 23.98 \\
$\varphi_{313}$ & 24.04 & 23.95 & 23.88 & 23.93 & 23.88 & 24.00 & 23.88 & 23.88 & 24.35 & 23.98 \\
$\varphi_{314}$ & & & 24.33 & & 24.15 & 24.22 & & & & 24.17 \\
$\varphi_{341}$ & 26.67 & 26.55 & 26.65 & 26.77 & 27.03 & 26.96 & 26.51 & 26.89 & 26.56 & 26.60 \\
$\varphi_{342}$ & 26.85 & 26.51 & 26.56 & 26.81 & 26.66 & 26.77 & 26.51 & 26.51 & 26.51 & 26.60 \\
$\varphi_{343}$ & 26.79 & 26.51 & & 26.85 & 26.51 & 26.51 & & 26.51 & & 26.82 \\
$\varphi_{344}$ & & & 26.82 & 27.80 & 27.18 & 27.02 & 26.83 & 27.12 & 26.84 & 26.96 \\
\hline
\end{tabular}

Table 7 Objective functions value in ten non-dominated solutions

\begin{tabular}{|c|c|c|c|c|c|c|c|c|c|c|}
\hline & Sol. 1 & Sol. 2 & Sol. 3 & Sol. 4 & Sol. 5 & Sol. 6 & Sol. 7 & Sol. 8 & Sol. 9 & Sol. 10 \\
\hline$z 1$ & 51453.48 & 48311.72 & 52604.68 & 52485.88 & 58471.23 & 57122.39 & 54163.06 & 58784.38 & 51554.93 & 57113.14 \\
\hline$z 2$ & 17.32048 & 16.77819 & 20.10106 & 19.47626 & 22.49809 & 22.70843 & 20.08323 & 24.0886 & 19.61641 & 21.78098 \\
\hline$z 3$ & 7.611193 & 6.677395 & 9.541605 & 9.021059 & 11.70642 & 11.14942 & 9.618793 & 11.69745 & 8.657602 & 10.457 \\
\hline $\begin{array}{l}\text { Changes in } \\
z_{1}, z_{2}, z_{3}\end{array}$ & & $\downarrow \downarrow \downarrow$ & $\uparrow \uparrow \uparrow$ & $\downarrow \downarrow \downarrow$ & $\uparrow \uparrow \uparrow$ & $\downarrow \uparrow \downarrow$ & $\downarrow \downarrow \downarrow$ & $\uparrow \uparrow \uparrow$ & $\downarrow \downarrow \downarrow$ & $\uparrow \uparrow \uparrow$ \\
\hline
\end{tabular}

Table 8 comparison results of two independent samples of solutions obtained by NSGA-II and SPEA 2

Ranks

\begin{tabular}{llrrc}
\hline Metric & Algorithm & N & $\begin{array}{c}\text { Sum of } \\
\text { Ranks }\end{array}$ & $\begin{array}{c}\text { Mean } \\
\text { Rank }\end{array}$ \\
\hline Set coverage & NSGA-II & 30 & 1065.5 & 35.52 \\
& SPEA 2 & 30 & 764.5 & 25.48 \\
\hline Spacing & NSGA-II & 30 & 907.0 & 30.23 \\
& SPEA 2 & 30 & 923.0 & 30.77 \\
\hline
\end{tabular}

Test Statistics

\begin{tabular}{lrr}
\hline & Set & \\
& Coverage & Spacing \\
\hline Wilcoxon W & 764.500 & 923.000 \\
Standard Error & 65.916 & 67.639 \\
Standardized Test Statistic & -2.283 & 0.118 \\
Asymptotic Sig. (2-sided & & \\
test) & 0.022 & 0.906 \\
\hline The significance level is 0.05 & &
\end{tabular}


Adversarial

Partnership
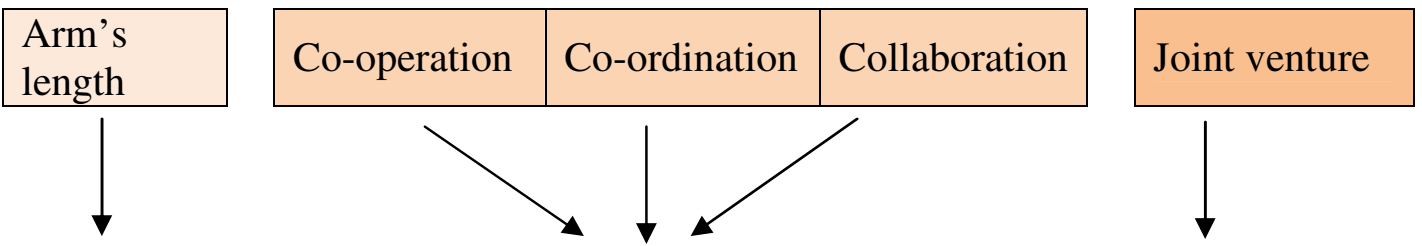

Integration

Emphasis on price

Emphasis on relationship
Emphasis on sharing risk and rewards through a legal entity

\section{Vertically}

integrated

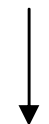

Supply chain owned and controlled by a single organization

Figure 1 types of relationship between buyer and supplier (Hines, 2004)

\begin{tabular}{|l|l|l|l|l|l|}
\hline$x_{111}$ & $x_{112}$ & $\ldots \ldots$. & $x_{i j t}$ & $\ldots \ldots .$. & $x_{I J T}$ \\
\hline \multicolumn{5}{|c|}{$x$} \\
\hline$y_{11}$ & $y_{12}$ & $\ldots \ldots .$. & $y_{j t}$ & $\ldots \ldots .$. & $y_{J T}$ \\
\hline \multicolumn{6}{|c|}{$y$} \\
\hline$p_{11}$ & $p_{12}$ & $\ldots \ldots$. & $p_{i t}$ & $\ldots \ldots .$. & $p_{I T}$ \\
\hline \multicolumn{6}{|c}{$p$} \\
\hline
\end{tabular}

Figure 2 Each chromosome consists of three types of variables, integer, 0/1 and real vectors. 

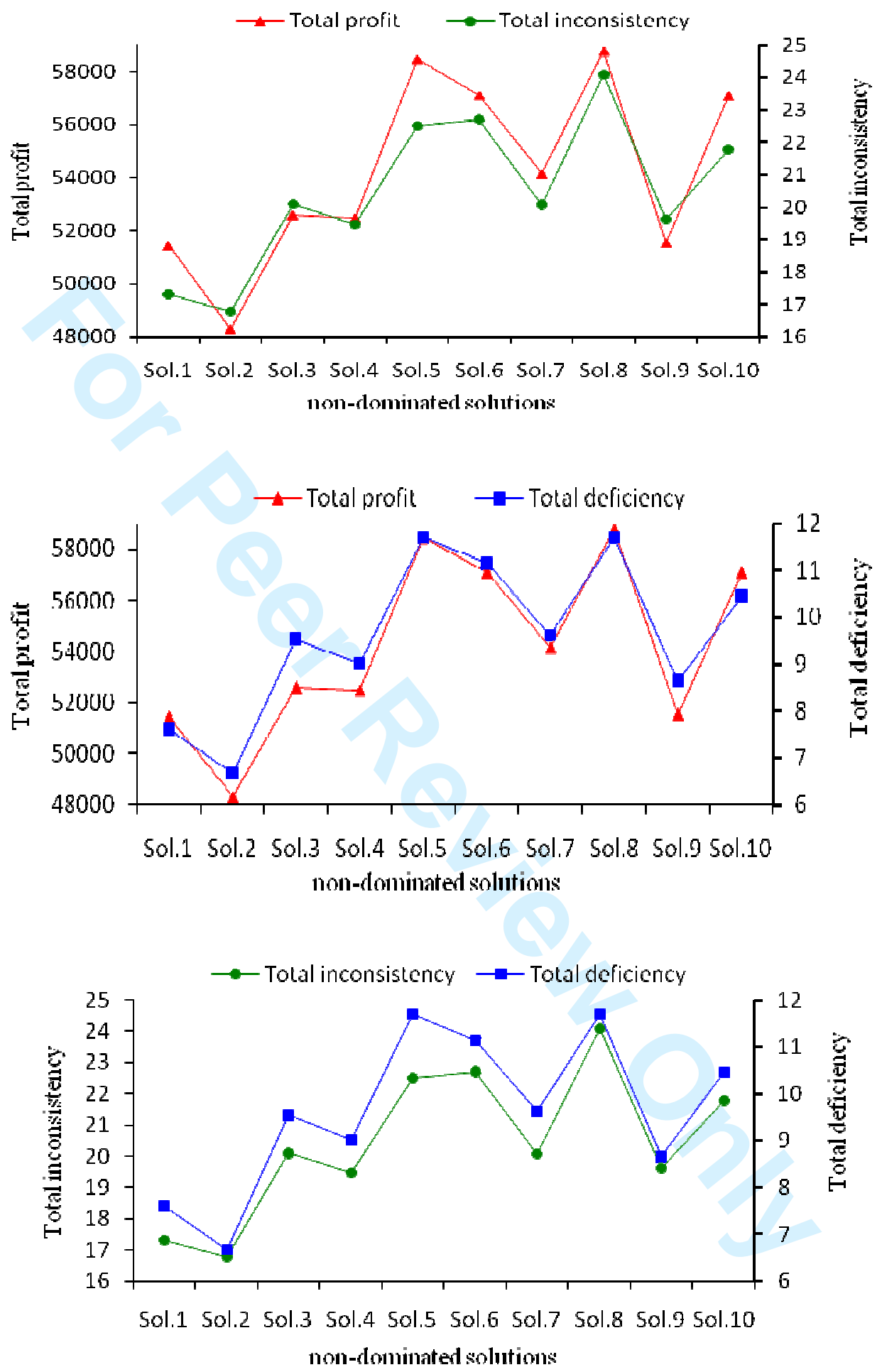

Figure 3 Total profit, total inconsistency and total deficiency of ten non-dominated solutions. 